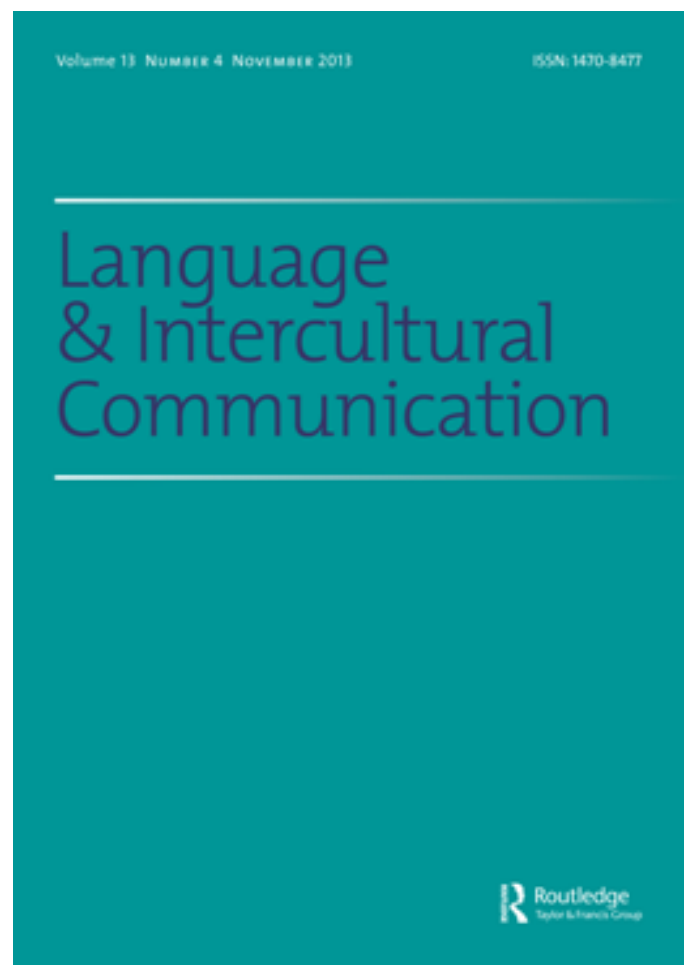

\title{
Re-visiting the Unhomely through Languaging
}

\begin{tabular}{|r|l|}
\hline Journal: & Language and Intercultural Communication \\
\hline Manuscript ID & LAIC-1176.R1 \\
\hline Keywords: & chronotope, unhomely, third space, time-space, languagers, becoming \\
\hline & $\begin{array}{l}\text { This paper will build on Bhabha's (1992, 1994) conceptualization of third } \\
\text { space and the 'unhomely' by turning to the power of the tangible, } \\
\text { material and ordinary aspects of the intercultural encounter. In order to } \\
\text { do this it focuses on the 'crisis points' that languagers encounter in their } \\
\text { biographies and puts forward a frame of analysis based on the concepts } \\
\text { of 'Chronotope' and 'Mudes' that places languagers' spatio-temporal } \\
\text { coordinates in synchronicity with their life itineraries. This analytical } \\
\text { framework is applied to the narratives of six language learners who } \\
\text { relate a 'critical moment' that enacts an ordinary event whilst } \\
\text { highlighting the subversive nature of the multilingual experience. I will } \\
\text { conclude that such interpretation of languagers' third spaces help us } \\
\text { seeing their identities as processes of becoming that challenge } \\
\text { homogeneous, static and abstract versions of the intercultural encounter. }\end{array}$ \\
\hline & Papstract \\
\hline
\end{tabular}

\section{SCHOLARONE" Manuscripts}




\title{
Re-visiting the Unhomely through Languaging
}

\author{
( 8,320 words, including references)
}

\begin{abstract}
This paper will build on Bhabha's $(1992,1994)$ conceptualization of third space and the 'unhomely' by turning to the power of the tangible, material and ordinary aspects of the intercultural encounter. In order to do this it focuses on the 'crisis points' that languagers encounter in their biographies and puts forward a frame of analysis based on the concepts of 'Chronotope' and 'Mudes' that places languagers' spatio-temporal coordinates in synchronicity with their life itineraries. This analytical framework is applied to the narratives of six language learners who relate a 'critical moment' that enacts an ordinary event whilst highlighting the subversive nature of the multilingual experience. I will conclude that such interpretation of languagers' third spaces help us seeing their identities as processes of becoming that challenge homogeneous, static and abstract versions of the intercultural encounter.
\end{abstract}

Aquest article es basa en la tesi del Third space $i$ el Unhomely (Bhabha 1992, 1994) lo qual posa èmfasi en el poder del que és tangible, material, i ordinari en l'intercanvi intercultural. Per fer això s'enfoca en els punts de crisi que els languagers troben a les seves biographies i proposa un marc d'anàlisi basat en els conceptes del Chronotope i Muda. Els citats conceptes posen les coordinades del temps-espai en sincronía amb els itineraris de les vides dels languagers. Aquest marc teòric s'aplica a les narratives de sis languagers que relaten un moment crític de l'experiència multilingüe quotidiana i la naturalesa subversiva d'aquesta. Per concloure, diré que la interpretació del Third Space ens ajuda a veure les identitats multilingües com a processos de transformació que qüestionen versions més homogènies, estàtiques i abstractes de l'intercanvi intercultural.

Keywords: chronotope, unhomely, third space, time-space, languagers, becoming, muda. 
2- Re-submission after referees commments_20/07/2018

\section{INTRODUCTION}

Whether we refer to ideas of identity and belonging to a particular culture or the materiality of the home, the feeling of warmth and comfort that is provided by having one's own space and place is something one has 'earned' through ongoing engagement with home-making. As Huppatz et al (2015) put it 'Places do not simply exist as homes. Rather, home is made through home-making practices that transform places (such as houses) into homes' (p.86). In this paper I argue that similar forces are at play with the construction of our cultural identity. We do not necessarily passively experience other cultures, but we make new cultural homes and identities through our actions, lives and daily practices, our trajectories and biographies. In this paper I argue that the intricate special relationship we create with the times and spaces we inhabit shape the intercultural encounter. As Phipps (2011) puts it, our cultural identities are created through 'worlds in action'.

I will explore how these cultural 'homes' and 'third spaces' are performed and lived outside pre-packaged and ideologically constructed cultures, a place where the unfamiliar and the personal cultural space rather than the Other may be explored. Bhabha (1994), who pioneered the concept of the Third Space, also characterized this in-between space outside official discourses as the unhomely. For him, the unhomely is the shock of recognition of the world in-the-home, and the home-in-theworld.

\section{Interrogating the notion of 'Home'}


The theory of the Third Space and the Unhomely helps us locate Languagers' trajectories outside the predictable essentialist positions and trajectories of monolingual and monocultural perspectives.

Indeed, both home-making and worlds-in-action entail the active engaging with languages and cultures so that the act of 'languaging' (Phipps 2011) can help us discover new ways of being in the world. Language-being-in-the-world means being in a state of permanent questioning of our surroundings and looking for ways of interrogating not only the language of the other culture, e.g. Spanish, English, Arabic, the clearly bounded entities, but also the messier cultures in between, the 'liminalities and the cracks on the walls of national cultures and their boundaries' (Bhabha 1994).

For Bhabha (1994), these unchartered Third Spaces are also subversive spaces. They are spaces that are located outside dominant ways of viewing the world and 'firmly focus on those moments or processes that are produced in the articulation of cultural differences' (p.1). So that the unhomely is a place where the dominant order is challenged. 'It's a negotiation of powers of cultural difference in a range of historical conditions and social contradictions' (Bhabha 1994:142). A confrontation of worlds where the hierarchies of the old worlds are challenged by putting stable inherited socio-historical meanings into perspective in order to question the foundations of the previously contained worlds.

It is not difficult to see how language learning and languaging can also be seen through these conflictual perspectives and how the language learner creates something new out of it. In this paper I will explore how encountering and speaking another language and culture often involves not only the deconstruction and dislocation of previously embodied 
cultural worlds, but also the exploration of new openings and directions anchored in one's ordinary life and biography.

\section{Domestic junctures}

The 'unhomely' both challenges dominant world representations and, more importantly, the conventional separation of time and space. Focusing on the unhomely of the Third Space then also means being interested in the 'moments of transit', in the junctures, 'where space and time cross to produce complex figures of difference and identity, past and present, inside and outside, inclusion and exclusion' (Bhabha 1994:1).

Indeed, for Bhabha, time and space are collapsed into one and the 'unhomely' becomes the passage-way between the past and the present. 'Unspoken unrepresented pasts [] haunt the historical present' (Bhabha 1994:147). And what is crucial here is that this moving tide through time and space does not happen in some general socio-cultural plane, but it seeps into language learners' most intimate domestic spaces. As Bhabha puts it, 'the recesses of the domestic space become sites for history's most intricate invasions' (Bhabha 1994:13). As we will see in the examples from ethnographic data from language learners shown in this paper, the domestic and the ordinary can acquire new protagonism: the buildings surrounding street cafes, the romantic family-recommended novels and the strolls through new familiar streets and street markets can be part and parcel of the material and the ordinary in the intercultural encounter.

\section{Languagers' materialities and itineraries}


The merging of time and space in Languagers' experience is best understood by focusing on their biographical trajectories. This article delves into the contingent, historical and mundane in the unhomely by focusing on 'the points of recognition' of languagers' itineraries, and how these critical points are situated and managed in the 'goings on' of everyday life. In particular, I will be investigating the ways in which the unhomely and the 'shock of recognition' are rooted in the temporality and spatiality of a specific point in time. The materiality of time-space gives us the opportunity to treat the present (and observable) practices of language learning not only from the here and now, but also from a historical point of view by looking for instances in which language learners reveal and 'speak out' unrepresented pasts.

Such understandings of identity and cultural home start from the premise that 'homeworlds' can be something malleable and dynamic across one's life-time and biography, and the possibility that the learning and living of additional languages can lead to the inhabiting of alternative cultural homes. Although this view of second and additional language learning is situated within a body of work that frames language learning as a personal, creative and spiritual endeavor (Anderson and Macleroy 2016, Coffey 2008, Kramsch 2009, Lytra, Volk and Gregory, 2016, Ros i Solé and Fenoulhet 2013, Phipps 2007, Quist 2012, Ros i Solé, 2016) which claims a subversive and emancipatory role for the languager (Coffey 2008, Kramsch 2009, Norton 2000, 2013), I will add to it a more grounded approach that focuses on the situatedness and performances of languagers' actions in time and space.

In particular, I will draw on studies in sociolinguistics that have emphasized the need to study the complexity of multilingual and 'New Speakers' cultural 
6-Re-submission after referees commments_20/07/2018

homes as mobile spaces and dynamic trajectories, and the need to explore the unpredictability of their paths and itineraries. Within this perspective, language journeys are not always determined at the outset, instead, they are journeys that are susceptible to change and, crucially, reversible (Woolard 2016, Ros i Solé and Fenoulhet 2011). Martín-Rojo and Rodriguez (2016) describe these journeys in their accounts of the spatio-temporal trajectories and the life histories of Spanish 'New Speakers' in Madrid's university campuses.

Building on the notion of the Unhomely and the New Speakers' literature, I will approach languagers' dynamic and fluid home-making through the analysis of the points of reflection in language learners' biographies and narratives in specific time-spaces coordinates. Such an approach will be underpinned by the use of the 'critical moment' unit of analysis and two theoretical notions: that of the Chronotopes and Mudes that, whilst referring to similar processes, they will also be complementary.

The unit of analysis of the 'critical moment' is defined as instances where the themes and actions of communication touch most closely on the personalities and ideologies of the participants, such that they for a moment, often quite dramatically, reveal those ideological, sociological, and political positions through their choices of, and responses to language' (Breen 2014: xviii). These 'critical moments' will be analysed in order to see how they unfold in time and space and will be explained in reference to two notions, that of the Chronotope (or the intersections of time and space) (Bakhtin 1981) and the sociolinguistics notion of Muda (a Catalan term used in Sociolinguistics for indicating a time of change, when somebody decides to adopt a new language as a functional language) (Pujolar and González 2012). 
7- Re-submission after referees commments_20/07/2018

The analysis of language learners' experiences in relation to Chronotopes and Mudes will allow us to throw new light onto the 'ordinary' and the 'contingent' in the biographies of languagers by constantly establishing links between the past, present and future. In particular, this study addressed the following question: How do language learners use time and space to give meaning to their dynamic homemaking and languaging itineraries? And, more specifically:

1) What processes of home-making do Languagers' Chronotopes reveal?

2) What moments of 'recognition' do examples of Muda establish in Languagers' stories? And,

3) How is movement between the past, the present and the future established in Languagers' 'critical moments'?

CHRONOTOPES AND MUDES: Multidimensional and transformative junctions.

The combination of literary studies (Bahktin 1981) and sociolinguistic (Pujolar and González 2012) lenses to studying language and culture will help us theorise the force of time and history inherent in the lived experience of multilingual speakers by building a more fluid understanding of cultural identity. Drawing on the notions of Chronotopes and Muda, I build a framework for looking at language learners' subjectivities as multidimensional junctions in languagers' lives. Whilst the concept of the Chronotope is used to discuss an understanding of language learners' descriptions of place and time and the synchronicity between the spatio-temporal axis and the progression of their linguistic personas; the sociolinguistic notion of Muda throws light on the "point of 
8- Re-submission after referees commments_20/07/2018

recognition', i.e. the specific time in which an individual decides to adopt a language as his/her 'functional language'.

I will now turn to the theoretical notion that I will be using to investigate a diachronic understanding of learners' identity: Bakhtin's (1981) conceptualization of the chronotope, literally (time-space).

\section{Chronotopes}

Bakhtin's idea of an interdependent time-space zone is defined by the 'intersection of axes and fusion of indicators [which] characterizes the artistic chronotope' (p.119). In Bakhtin's humanistic version of the timespace relationship, the two are fused into a concrete organic whole that is in synchronicity with its environment. In order to respond to each other, time and space change into new textures as they react to new geographic and chronologic positionings 'Time, as it were, thickens, takes on flesh, becomes artistically visible; likewise, space becomes charged and responsive to the movements of time, plot and history' (p.119).

Indeed, languagers' biographical journeys are varied and complex (Ros i Solé 2016) and one could argue that they are constituted by a series of key moments in their paths, 'chronos' (times), and 'topos', (places). Places where language learners feel inspired to reflect, where intense feelings develop, and where new relationships are built.

In Bakhtinian literary theory, Chronotopes are what gives meaning to the narrative:

'The chronotope is the place where the knots of narrative are tied and untied. It can be said without qualification that to them 
belongs the meaning that shapes narrative' (‥) 'time becomes, in effect, palpable and visible; the chronotope makes narrative events concrete, makes them take on flesh, causes blood to flow in their veins $(\cdots)(\mathrm{p} 250)$

The idea of the Chronotope then allows us to ground the experience of the languager to a particular time-space coordinate that connects them to specific events. These Chronotopes may be the scene of intense emotion: the learner may experience: the getting 'enamoured' with the language -fascinated by the mystery and mystique of specific events and places (Kramsch 2009), like feeling in awe at the visualization of Arabic writing on the wall, or, on the contrary, feeling the experience, the discomfort of having to wrestle with new values and processes of 'disidentification' (Braidotti 2010) that helps understanding a so-far accepted culture (McNamara 2013).

Chronotopes are therefore harbingers of intense emotions: aesthetic feelings that take one's breath away, or sudden and painful awareness of an internal conflict. In fact, the affect contained in the Chronotope may be so intense that it may result in new 'body memories' (Busch 2014) or traces in the languager biographical history. Time and space witnesses each other and together they scaffold how the narrative of the languager unfolds.

But the Chronotope in Bakhtin's dissection of the novel is not only used to describe time and space coordenates but they are also seen as the knots that advance language learners' trajectory-plots. As Bakhtin (1981) poses in reference to literary analysis 'the plot-movement' (p.124) of the novel develops structured around series of time-related biographical events that shape the story, e.g, the first meeting of the 
10- Re-submission after referees commments_20/07/2018

hero and heroine, and their marriage and successful union at the end. Other Chronotopes, such as specific parts in a building, or the scenes of a provincial town, can also become the key time-space for the denouement of the story and the transformation of the characters.

But before I show some examples of languagers in which time and space is used to advance the plot of their language biographies, we will turn to the notion of Mudes, which will further clarify how movement is achieved in languagers' trajectories and how this movement is characterised.

\section{Mudes}

The term Muda is a Catalan term that means 'a variation in social performance (often reversible) such as dressing up for an event or change of appearance generally' (Pujolar and Gonzalez 2012: p.168) and it highlights the changeable and unpredictable nature of one's linguistic repertoire and the point at which subjects transform themselves and their language practices by adopting new forms of self-representation (Pujolar and González 2012). Self-representations are then brought about as a result of changing language practices and adopting new Mudes that last as long as the social juncture and performance requires it.

Although this sociolinguistic term was originally used to talk about the use and adoption of a second language in contexts of migration and immersion into another culture (the adoption of Catalan by Spanish speakers), I will apply it to that of the languager who is learning and speaking an additional language that is not the majority or official language of the social environment. 
The notion of Mudes will add to the notion of Chronotopes by putting emphasis on the movement and the notion of time in languagers' trajectories. Following Pujolar and González (2012) I will interpret the notion of Mudes as critical moments that help us appreciate languagers' trajectories as multiple paths or 'biographical junctures'. Such a vision of linguistic identities puts the emphasis on the dynamic and multiple practices and performances that languages are put to and on the trigger for these performances. The linguistic performance here is defined by the time and purpose to which languages are 'socialised' (whether this is of a practical, leisure or affective nature). In this way, the adoption of new uses for the language adds the possibility of change and movement throughout one's life moving away from the old static sociological categories (Pujolar and Puigdeval 2015: 169).

In my research I will be particularly interested in how this movement and change is established in languagers' biographical itineraries by looking at what the social triggers for their 'moments of recognition' are and the social circumstances in which these changes occur. Whereas the Chronotope makes time concrete and gives it flesh by framing the event through the description and advancement of the narrative, the Muda further identifies that movement through the performance of a particular social interaction.

\section{METHODOLOGY}

The methodology employed in this study is ethnographic in perspective and style (Agar 1996, Green and Bloome 1997). As such, it gives emphasis to the richness and the detail of the accounts of language learner so that they help us stay as closely as possible to the informants' worlds (Harris 2006, Wolcott 1994). In our case it helps us see how languagers construct their own stories through their narratives and how 
12- Re-submission after referees commments_20/07/2018

they are firmly embedded in their experiences, daily practices, circumstances and history (Blommaert 2005).

The study has drawn from two different data sets: one of 7 language learners' interviews of learners of Catalan, Arabic and Croatian/Serbian over 6 months, personal written diaries and ethnographic observations conducted in 2008 and a data set of 20 adult language learners of Spanish in a UK university who were interviewed for half an hour in 2004 with a focus on their learners' identities. I have extracted what I have called 'critical moments' for the analysis. These narratives do not appear in isolation but were extracted from larger narratives in interviews and diaries. The analysis of the data is based on a framework where these units were identified, and subsequently interpreted with the notions of Chronotopes and Mudes.

In the analysis of Bahktin's Chronotopes we will concentrate on the Chronotope of the 'Threshold' that evidences the dynamic processes involved in languagers' home-making and as contrast to the routinized and uneventful ancilliary or secondary time of the story. So that, while the ancilliary time describes and pins down the scene to a particular time-space, the Threshold Chronotope indicates the break in the story, and is the instigator of the plot-movement.

The Threshold is the type of Chronotope that defines moment of intense emotion where there is a realization and an epiphany in the biographical time of a character. Threshold Chronotopes are moments of decision and of change of direction in the course of one's life 'the places where crisis events occur, the falls, resurrections, renewals, epiphanies, decisions that determine the whole life of a man' (Bakhtin 1981:248) 
13- Re-submission after referees commments_20/07/2018

\section{DATA ANALYSIS}

In this section I analyse four interview extracts and a brief field-note, where six students relate their language learning experiences and how these were connected to their biographies. The students whose real names have been changed to preserve their anonymity, were postgraduate students (the first three) and an undergraduate mature distance language learner (Abby). Olga and Weronika and two anonymous students of Serbian-Croatian, whereas Emma is a student of Arabic, and Abby, an undergraduate student of Spanish.

\section{Languagers' Chronotopes}

In the first extract I will discuss how Olga expresses a 'critical moment' in her narrative of how she became a language learner of SerbianCroatian and a critical point in her biography. In this moment, Olga reveals a turning point where her personality and ideological stance undergo change in relation to the notion of place and time. This occurs through the identification of the physical travelling of the character of the novel with Olga's progression into the studying and interest for SerbianCroatian.

It actually started when my mum gave me a book that was written in the 1930s/40s about this woman travelling through (‥). It's called Illyrian Spring, sort of along the coastline. So I had this kind of romantic notion. And then also Yugoslavia, this socialist history (...) It's this woman, it's fiction. I think it was written in the 30s or 40s (..) She is kind of this upper class woman who gets really fed up with her husband so she just walks out of her family and she is going to Greece and she sets off by train and she travels all the way through but she gets to Illyria and Dalmatia. And she never gets any further. And she meets with these amazing characters. She has this fantastic 
14- Re-submission after referees commments_20/07/2018

love affair and all this sort of stuff. So I just had this incredible romantic view (Olga, Interview)

(This extract is also reproduced in Ros i Solé (2016:38)

In Olga's extract above, we see how the personal pronoun 'it' refers to the turning point in her biography. The 'it' refers to the critical moment which is the point of the story. Although the story starts in a very tentative fashion with phrases like 'this kind of $\cdots$ ' and is kind of this upper class' (line 3-5). In line 7, we see that Olga starts using the intensifiers (e.g. 'really', 'never', 'fantastic', 'amazing', 'incredible). The language used reflects the importance and intensity of emotion that Olga places on the character of the novel, who is acting as an alter-ego for her fascination for Croatian culture and her own personal journey.

Olga's inspiration on the character of a novel and her exoticised view of another country is nothing new. The trope of escaping from a familiar and domesticated life to a place of liberation is a theme that has already been well-documented in the literature of language learning (Kinginger 2004, Pavlenko 2001, Kramsch 2009, Coffey 2014, Ros i Solé 2016). However, what has perhaps been less evident in the literature so far is how the notion of place and time are being used in synchronicity with the development of the character described (and in this case, the student herself) in accounts of second/additional language learning and intercultural communication. Olga sets the scene with the 'ancillary time' of the old routinized life of the character, which she indicates with her more vague language at the beginning of her anecdote. Then, she contrasts this ancilliary, vague and sleepy time 'sort of along the coastline', 'kind of romantic notion', it's socialist history' 'kind of this upper class woman' (lines 3-6) with the more vibrant language of the second half of the story that is introduced by the dramatic sentence 'And 
she never gets any further' (line 10). After this, every sentence is preceded by a qualifying adjective to denote that something extraordinary has happened.

The character changes from a static, cyclical and uneventful life of monolingualism that could be compared to the description of a provincial time that Bakhtin makes in her analysis of Emma Bovary's tedious surroundings full of 'sleepy streets, the dust and the flies, the club, the billiards, and so on and on' (p.248), to a more exciting existence of inhabiting another language which breaks with the past and offers excitement and novelty.

Like in Flaubert's novel in Bakhtin's account (1981) and the building of the heroine's character, for Olga, a student of Serbian/Croatian, the studying of Croatian coincides with a new dynamism in her life: her new life itinerary now becomes susceptible of having "meetings", "partings", in short, it has left the ancilliary time of the 'sort of upper-class life' and has crossed a Threshold in the story that sets her off in a different direction. This is the critical moment that allows Olga not only to advance the plot of her language trajectory, but it also subverts the dominant order of things of her previous culture and as Bhabha (1994) points out, it becomes a liminal and unhomely place where the natural order of things is challenged.

We find a similar subversiveness in a student of Arabic, Emma. She also uses the narrative hiatus of a 'critical moment' to show how an event from the past provokes a 'crisis' in her trajectory and sets her off on a different path.

They [her parents] don't comment on it as such. I think that when I first said I was going to Morocco they were really worried because, I guess just because of things you hear. The 
16- Re-submission after referees commments_20/07/2018

associations made, I guess in the media, not that they $\cdots$ but they were just worried. And then they came over and they were a bit shocked of the surroundings but they kind of got used to it, as I was when I first went there. I arrived in the middle of the night into one of the old towns and I was first stunned 'oh dear'. In the first day it was like really hussely and bussely and obviously the only white person around, so it is a bit strange but I got used to it because I was there for a while. It is a bit weird. But now, I am thinking of going to the West Bank in the summer.

\section{(Emma, Interview)}

Like in the previous narrative, here we can identify a point of recognition, which is when Emma realizes that her experiencing of Arabic culture as everyday life prompts her to re-appraise her past life. It is an unexpected development of events that is connected to time and space, e.g. her arrival in the middle of the night (a dark and mysterious place) and the subsequent getting used to the surroundings, e.g. 'But I got used to it because I was there for a while' (lines 10-11). For Emma, one of the critical moments in her experiencing of Arabic is linked to a very specific location and description of a place, when her parents come over and experience the same emotions, the same sense of 'strangeness'. The key 'critical point' then is when she realises that, unlike them, she has moved on in her biography and is already inhabiting another space.

Emma's critical moment could be described as a 'coming of age' in her life itinerary: e.g. the moment she recognizes that she is independent from her parents' lifestyle and their worry and fear of the 'other'. Through this narrative, we can identify a shift in her trajectory. Emma's appreciation of Morocco changes from an official and dominant version gleaned from the news and surrounding discourses, to her more grounded experience situated in time and space (first in the old town in 
Morocco and then in the West Bank 'this summer'). This contingent and material version of the cultural encounter contrast with the imagined media discourses of Moroccan and Arab culture that both Emma and her parents have drawn on.

Like in Olga's account, experiencing the language and culture gives Emma the opportunity to challenge these dominant ways of seeing. In this extract we see how this is done in a particular Chronotope of the story. Here, Emma's parents' version of Morocco is presented as the 'ancilliary time', the background of the story, whilst the Threshold Chronotope introduces a break from this prejudiced version of the culture. Such a rupture, however, is presented not as a dead end but as an opening for new opportunities and the development of new emotions. In contrast to her routine and domestic past, now life is infused with intensity. Although the unhomely is destablizing, it's 'a bit strange', 'a bit weird', and it even provokes an 'oh dear', it is also the beginning of something new, it is the happy 'hussely and bussely' atmosphere that gives way to a new state of mind.

Whilst the breaking with the past and the challenging of a previous familiar order sets the scene for a new version of the culture, it is by building a passage from the past to the present that Emma makes the leap from the ordinary to the extraordinary. It is by putting the threads of her past, her present, and her future (her mentioning of her impending visit to the West Bank while reviewing the past) together that she is able to make her new home, to turn her place-in-the-world into something new, a new trajectory. It is here that past and present collapse into one and, as Bhabha (1992) points out, she is able to bring into her present those unrepresented pasts from her biography and construct a new liminal Third Space. 
18- Re-submission after referees commments_20/07/2018

\section{Architectural Thresholds}

But these changes of tempo and locality are not only dependent on idyllic and romantic visions of another culture. The seemingly sleepy silence of a street café in Sarajevo observed by a student of Serbian-Croatian can also be disrupted, brought to life and populated by the painful visions and reminders of a past war. Here, the marks of bullets on the wall and its bloody connections serve as a contrasting Threshold Chronotope that spurs life into action:

One of the students told the anecdote that she once was sitting in a cafe having a drink and just opposite there was this building completely battered in the war. She felt awkward. Another student said how sad it was to still have all these places in Serbia where the place was completely 'level'. Although it was more than seventeen years ago nothing had been done about it.

(Field notes, Meeting with students at café in Bloomsbury, 3/12/08)

Here the researcher who relates the conversation of two different students and the deep impressions that surrounding buildings made on them, locates the Threshold and movement of the plot, not on the actions, but on buildings and architecture. What could be taken as the backdrop of the main action of a plot (the buildings that surround the person sitting in a café), become instead the plot-movement for the narrative. The physical surrounding is what spurs the action of the story, what produces the intense emotion. As these two students tell me (reflected in the researcher's field-note observations above), the buildings around them made an impression on their mind and feelings, 'she felt awkward, 'she felt sad' (lines 3 and 4) to another place and 
(possibly) made them reflect about their relationship with the culture and their position in it. These are instances of how the ordinary and the material of everyday life are woven into the story to explain the shock of recognition of two different worlds that now have been represented together in the Third Space of the 'unhomely'.

As we have seen with Emma's story and now my re-telling of the effect of the battered architecture on students' emotions, the Chronotope of the Threshold can also be located in an urban landscape and can be the main action and nexus for the development of the trajectory-plot of the languager.

Finally, I will show another 'critical moment' that disrupts a monotonous landscape where the home-making of the language and culture is not a 'given', but it is made out of a patchwork of cultures that are observed, dissected and subsequently put together. This is the story of Weronika, our third student of Serbian-Croatian who, by scrutinising her surroundings, identifies a culinary and diasporic version of SerbianCroatian culture.

'I am in Berlin now, which has a large 'post-Yugoslav' population. Even in Neukoln, which after Kreuzberg, is home to the largest Turkish diaspora. I can see a shop named Balkanische Spezialitaten - Balkan Specialities. What are the Balkan Specialities? I can't know for sure because the shop is closed now, but I'm sure one could find Ajvar (a paste made of smoked and grounded peppers), Sarma (stuffed wine leaves), Prsut (like Italian prosciutto), Kayinak cheese and other delicious things.'

(Weronika, diary) (1) 
20- Re-submission after referees commments_20/07/2018

In his extract, Weronika, a woman of Polish heritage, projects the diasporic culture of post-Yugoslavia onto the culture of the city of Berlin where she is staying. In the extract above, the 'unfamiliar shop' in a neighborhood in Berlin embodies another Chronotope Threshold in the plot of the story by disrupting the normal occurrence of things in a city and its ordinary goings on. The occurrence of the shop in the story 'jolts' the matrix of time and space by situating an unexpected sight in an otherwise familiar urban landscape. This creates a new networkconnection in the narrator's story of transnational proportions, one where German and post-Yugoslav cultures infuse new meaning into Weronika's representation of the world.

We can infer from this that this 'unfamiliar shop' constitutes an architectural Threshold Chronotope and one that is not dependent on political boundaries and one-language, one-nation relationship. Instead it models itself on a more dynamic and fluid concept of culture, one that Weronika immediately feels identified with. Indeed, it is in this small instances of languagers' ordinary lives that there is a rupture to homogenous city landscapes, where there is a break in the domesticity and routine life of a city.

Finally, we could say that events in languagers' biographies are characterized by sequences of events that are punctuated by Threshold Chronotopes where the advancing world of the languager takes a new direction and creates a new opening in life 'a decision that spurs life into action' (Bakhtin 1981:248).

Whilst the safe cyclical and ancillary time of a homogeneous culture and routinized life reaffirms one's identity, the Threshold Chronotope takes a more abrupt and sudden character, and immediately infuses the 
languager's biography with emotion and value. Like characters in a novel, languagers both narrate and embody their own stories. They start their journey at a particular point in time and space and are guided by a structure-plot that is driven and punctuated by events that are firmly anchored in time and space, whether these events drive towards a single, unmovable objective, or there is a crisis that modifies the story and character's trajectory.

So far we have looked at how the turning points in one's biographies have been brought about by the scenery or by the languagers' relationship with objects of the culture, a book, a building, etc... But how is the languager affected by his/her socialization processes with speakers of the new language? The concept of Muda below will address this aspect of languagers biographical junctures. In the next extract I discuss how an apparently mundane and ordinary activity such as going to the supermarket becomes a milestone and a 'critical moment' in a student of French (Abby) and her self-perception as a speaker of a foreign language.

Abby shows how at the biographical juncture of interacting with some locals in a shop and, whilst being on holiday with her husband in France, she came upon the realisation that she was capable of functioning in another language. This, however, was not an isolated incident as it determined her motivation for learning Spanish, the language she was studying at the moment of the interview, and was able to make this link and to see the implications that a positive experience in the past had 'enduring implications that unfold over (life)time' (Pujolar and Puigdeval 2015:169). The following extract shows how a seemingly functional focus can turn into a biographical event in the building of a languager's identity. 
22- Re-submission after referees commments_20/07/2018

Interviewer- What has been the most memorable language learning experience so far?

Abby- Um, I don't know, I remember, actually when we were on holiday in France last year somebody in the supermarket actually thought I was French and I wasn't actually speaking it but they came up and asked me something in French and actually I knew what they were talking about, they were asking me where something was and they knew what I actually told them and my husband said, 'actually, we are English' and they said, 'oh why didn't you say?' and I said 'well, I didn't need to, I answered your question' and I thought, that was quite good.

\section{(Interview, Abby)}

It is important to note how in this extract there is, on the one hand, an emphasis on the time and space when the event happens "when we were on holiday in France last year' (lines 3 and 4), but there is also something else going on: there is a very specific effort to capture a moment of change, a moment in which there is a realisation. This is expressed with the adverb 'actually' (line 3), which emphasises that there is something that disrupts the order of things, something unexpected. And the event that she relates reproduces such a shift in the ordinary course of things: her metamorphoses or transformation from being a learner of French to being a 'speaker' of French.

Although the critical moment is brief, such a realisation has great implications for Abby, who has picked up this particular anecdote as the most positive experience she had when learning a language. This account agrees with the notion of Muda and Threshold Chronotope not only because there is a momentary break in her linguistic identity, but also because it indexes a "life investment with open meanings' (Pujolar and Puigdeval 2015: 169) in a foreign language.

The fact that Abby tells us this story now that she is learning Spanish, and a few years down the line, indicates what an impact this event has had in her 
learning of foreign languages. Like Pujolar and Puigdeval (2015) have indicated, speakers invest in languages because speaking these languages have social consequences. In Abby's case, the social consequence is that of feeling that she can now pass as a speaker of another language, as this has now been 'legitimised' in negotiation with speakers of that community. We can see that her legitimisation here is double, first by the French couple who asks for a particular product in the Supermarket, and afterwards, by her husband who has to point out that they are English.

But as the term Muda indicates, a shift into another language is not a definite identity positioning or move, since language is not merely a fixed and static system of signs but it is also performative and reversible. As we see at the end of the extract, Abby goes back to being 'English' when her husband intervenes in the conversation and the magical spell of passing as French is broken: 'actually, we are English' and they said, "oh why didn't you say?" and I said "well, I didn't need to, I answered your question" '(lines 9-11). Indeed, the fleeting nature of the concept of Muda described by Pujolar and González (2012) suits the nature of additional language learning and use and the practices of the languager.

This extract also signals that Abby was for a brief moment in her biography able to adopt a 'French' persona and decided to adopt French as her 'functional language'. Such an event has an effect not only on Abby's linguistic repertoire but also on her cultural identity as she feels proud, for a brief moment in her life, of having passed as French and it signals that linguistic identities are not homogenous, but multiple and changing. With this brief example I have argued the possibility that cultural identities are not always tied to particular static categories such age, geography and class, but that through specific performances or Mudes in biographical junctures of 
24- Re-submission after referees commments_20/07/2018

one's experience of language learning over a lifetime, languages can be uncoupled from static and rigid notions of belonging and use.

\section{DISCUSSION AND CONCLUSION}

We started this paper by proposing to further the discussion on the third space proposed by Bhabha (1992) and revolving this discussion around the notion of home-making as a world-in-action, a dynamic and contingent process of subjectivity-making. I have done this by situating the narratives of languagers in specific spatio-temporal co-ordenates where either the context, scenery of languagers' stories, or the social interaction they engaged in provided the trigger and the moment of crisis and recognition in their language learning and life trajectories. The research questions then set out to identify how these processes were realized in the mundane and ordinary lives of languagers of Serbian/Croatian, Arabic and Spanish by identifying 'critical moments' where such processes could be traced. Below, I will refer to the three research questions posed at the beginning of this article in turn.

1) What processes of home-making do Languagers' Chronotopes reveal?

I have argued that Language Learners' use of the Threshold Chronotope is used to contrast the dominant and established time of their monolingual lives, the slow and sticky time, with a more dynamic and exciting tempo, that of the 'languager' time that brings epiphanies, falls and renewals. 
The Threshold Chronotope brings to the languager a sudden stop to their trajectories and their biographies, but also a moment of recognition that brings an intensity of emotion and the need for a new lense to appreciate the now less-than-ordinary surroundings and daily goings on. Whether it is to conquer the fear of an intimidating and unfamiliar street scene where one stands out (Emma), to take in the painful history of a bloody past through the appreciation of battered architecture (scenes in exYugoslavia), or to surrender to the pull of a fantastic story that urges us to break with the familiar and the domesticated (Olga), the languager has taken a new turn in all these languagers' biographies. The world-in-thehome is evidenced in the narrative through the contrasting of circulating narratives of the Other embodied by Emma's parents, the noticing of the legacy of war in the mundane and leisurely activity of drinking coffee in a public place or the expanding of one's horizons by embarking on an imaginary trip through the readings of a romantic travel novel.

2) What moments of 'recognition' do examples of Muda establish in Languagers' stories?

If the Threshold Chronotope allowed to identify the falls and the resurrections in relation to one's surroundings and added tempo of the story, the Muda brings home the influence that the languagers' engagement in social interaction will bring to this moments of crisis and biographical junctures. We saw how in the example from Abby the social exchange between the French couple and the English couple provoked a sudden realization for Abby, one that marked a new knot in her language trajectory that allowed her to momentarily become a speaker of French, and made her capable of escaping the limitations of a static identity. Instead, she claims for herself a much more contingent, unpredictable and reversible linguistic and cultural home. This reversible and dynamic nature of her identity can be summarized by a sudden re-alignment to 
26- Re-submission after referees commments_20/07/2018

her English self, e.g. "actually, we are English" and they said "oh why didn't you say?".

3) How is movement between the past, the present and the future achieved in Languagers' 'critical moments'?

We advanced at the beginning of this article that language learning was going to be looked at not only from the ordinary of the here and now, but also from a historical perspective that invoked 'the unspoken unrepresented pasts that haunt the historical present' (Bhabha 1992:147) so that we are able to establish a passage-way between the mundane and the transcendental in the intercultural experience. I have shown in the data that the languager is made out of critical moments and welcome disruptions in one's biography. But these should not be seen as irreversible ruptures with the past and the future, rather as an organic weaving of different threads in the language learners' lives and of multiple and reversible directions. Threads and leads that stick out to be picked up for further weaving of one's life story. Olga picked on her mum's recommendation of a book and followed her traced path. Emma broke free from the security of her usual surroundings and made links with her sheltered past in the family household, whilst clearly pointing to a future in the West Bank. Finally, the 'critical moment' that Abby provides in her anecdote from her shopping in France also corroborates the embeddedness of languagers' homes within a subjectivity-inprogress (Kramsch 2009), like Abby's English-French-Spanish-English linguistic identifications and homes.

A re-reading of multilingual speakers and the cultural encounter that focuses on the spatio-temporal implies a new way of looking at the identity and subjectivity of the language learner; one that rejects static and non-agentic 
approaches to identity in favour of the contingent and the multiple. In this paper, I have argued that we do not have one past, one present and one future, but as Braidotti says (2010:408) instead of deference to the authority of the past, we have the fleeting co-presence of multiple time-zones, in a continuum that activates and de-territorializes stable identities'.

In today's mobile and superdiverse world, even at the heart of post-colonial Europe, the existence of third, liminal spaces is not a given, and the concept of home is still a highly disputed notion. So, rather than conceptualizing homes as abstract and ideological entities, I have argued that homes can be seen as ordinary linguistic and cultural practices on the move. The idea that languages and cultures are rooted in time and space has constructed a new lense with which to analyse languagers' subjectivities. The focus on how these Chronotopes are organized in languagers' narratives has shown that there may be something novel at work, i.e. languagers' privileged position for engaging not only with new cultural worlds in the abstract, but also with cultural practices in specific nexus and junctures in time and space. With their ordinary and yet subversive linguistic and cultural performances, languagers may be beacons of creative Third and Unhomely spaces that push the boundaries of cultural borders and escape the ideological monolingual and national-bound positions in which they are set to grow. Languagers can be seen as cultural 'home-makers' who can recognize and act out the necessary daily practices and performances that build unexpected passages between public and intimate worlds, past and present. Through language learning, languagers explore more than the representational and communicative function of language in some undefined time and space. Whether we situate languagers in Bhabha's post-colonial discourse or today's Brexit climate of complex transnational relations, we would do well to look at the little battles and the knots untied in personal narratives of languagers' trajectories. After 
28-Re-submission after referees commments_20/07/2018

all, languagers' home-making maybe less about constructing imaginary, officially-controlled spaces, but about subverting these 'natural orders' and artificial homes to create new possibilities for richer and vibrant cultural personal worlds.

\section{References}

Agar, M. (2006). The Professional Stranger. London: Academic Press.

Anderson, J. and Macleroy Obied, V. (eds.) (2016). Multilingual Digital Storytelling: Engaging creatively and critically with literacy. Oxford: Routledge.

Bakhtin, M. (1981). The Dialogic Imagination. University of Texas press.

Beck, U. (2006). The Cosmopolitan Vision. Cambridge: Polity Press.

Bhabha (1992). The World and the Home. Social Text, No. 31/32, Third World and Post-Colonial Issues (1992), pp. 141-153

Bhabha $(\cdots$

Blommaert, J. (2005). Bourdieu The Ethnographer. The Translator 11 (2), $199-236$.

Block, D. (2007). The Rise of Identity in SLA Research, Post Firth and Wagner (1997). Modern Language Journal, 91 (s1), 863-876.

Braidotti, R. (1991). Nomadic Subjects: Embodiment and Sexual Difference in Contemporary Feminist Theory. Columbia University Press.

Breen, M. (Ed) (2014). Learner contributions to language learning: NeW directions in Research. London: CUP.

Busch, B. (2014). Linguistic Repertoire and Spracherleben, the Lived Experience of Language. Working Papers in Urban Languages and Literacies, 145. London: King's College London.

Coffey, S. and Street, B. (2008). Narrative and Identity in the "Language Learning Project". The Modern Language Journal. Volume 92 (3) , pp. $452-464$. 
Coffey, S. (2011) Modern Language learning as a figured world of privilege. Mobility and Localisation in Language Learning. Fenoulhet, J. \& Ros i Solé, C. (eds.). Oxford ; New York: Peter Lang, p. 51-77

Coffey, S. 2014 Language learning and making the mundane special. Linguistic Approaches to Emotions in Context. Baider, F. \& Cislaru, G. (eds.). Amsterdam: John Benjamins, p. 331-346.

Cook, V. (1999). Going beyond the native speaker in language teaching. TESOL Quarterly 33 (2) pp.185-210.

Chen (2017). Foreign Languages as Cultural Capital. The Teaching. CLCL Seminar, $6^{\text {th }}$ Dec. University of Goldsmiths.

Green, J. \& Bloome, D. (1997). Ethnography and ethnographers of and in education: a situated perspective. In J. Flood, S. Heath, \& D. Lapp, D. (Eds.), A Handbook of Research on Teaching Literacy through the Communicative and Visual Arts (pp 181-202). New York, Simon and Shuster Macmillan.

Harris, R. (2006). New Ethnicities and Language Use. Hampshire: Palgrave.

Quist, G. (2013). Reading with my eyes open: embracing the critical and the personal in language pedagogy. UCL Arts and Humanities Publications. (1st ed.). London: Ubiquity Press.

Kinginger, C. (2004). 'Alice doesn't live here anymore': foreign language learning and identity reconstruction. In A. Pavlenko \& A. Blackledge (Eds.) Negotiation of Identities in Multilingual Contexts. Clevedon: Multilingual Matters.

Kramsch, C. (2009). The Multilingual Subject. Oxford: Oxford University Press.

Lytra, V., Volk, D. and Gregory, E. (2016). Navigating Languages, Literacies and Identities: Religion in Young Lives. London: Routledge.

McNamara, T. (2013). Crossing boundaries: journeys into language. Language and Intercultural Communication 13 (3) pp 342-356.

Omoniyi, T. (2006), Hierarchy of Identities: A Theoretical Perspective. In T. Omoniyi and G. White (Eds.) The Sociolinguistics of Identity. London: Continuum.

Pavlenko, A. (2001) "In the world of the tradition I was unimagined": negotiation of identities in cross-cultural autobiographies. The International Journal of Bilingualism 5 (3), 317-344.

Phipps, A. (2007). Learning the Arts of Linguistic Survival Languaging, Tourism, Life. Clevedon: Multilingual Matters/Channel View Publications.

Phipps, A. (2011): Travelling languages? Land, languaging and translation, Language and Intercultural Communication, 11:4, 364-376

Pujolar, J. and González, J. (2012). Linguistic 'mudes' and the de-ethnicization of language choice in Catalonia. International Journal of Bilingual Education and Bilingualism 16 (2), pp. 138-152. 
30- Re-submission after referees commments_20/07/2018

Pujolar, J. and Puigdeval, M. (2015): Linguistic Mudes: how to become a new speaker in Catalonia. IJSL 2015; 231: 167 - 187 < https://www.degruyter.com/downloadpdf/j/ijsl.2015.2015.issue-231/ijsl2014-0037/ijsl-2014-0037.pdf>

Rampton, B. (1990). Displacing the native speaker. ELT Journal. 44 (2).

Ros i Solé, C. and Fenoulhet, J. (2011). Language learning itineraries for the $21^{\text {st }}$ century. In Fenoulhet, J; Ros i Sole, C; (2010) Mobility and Localisation in Language Learning. [Book]. Intercultural Studies and Foreign Language Learning: Vol.5. Peter Lang: Oxford.

Ros i Solé, C. (2013). Cosmopolitan speakers and their cultural cartographies. The Language Learning Journal. 41 (3) pp. 326-339.

Tester, K. (ed.). 1994. The Flaneur. London: Routledge.

Street, B. (1993). Culture is a verb: anthropological aspects of language and cultural process. In D. Graddol, L. Thompson \& M. Byram. Language and Culture (pp. 22-43). Clevedon: British Studies in Applied Linguistic/Multilingual Matters.

Wolcott, H.F. (1994). Transforming Qualitative Data. Description, Analysis and Interpretation. London: Sage.

Woolard, K.A. (2016). Singular and Plural: Ideologies of Linguistic Authority in $21^{\text {st }}$ Century Catalonia. Oxford: Oxford University Press. 
LAIC-1176.R1 - Re-visiting the Unhomely through Languaging

I have revised my manuscript throughout taking into consideration the two anonymous reviewers' feedback. Below I outline, point by point, my answers to their comments:

\section{Referee 1:}

In respect to Rerferee 1, have worked on the points of contact between the unhomely, the concept of 'Mudes' and the concept of the 'Chronotope' at different points in the article, in particular at the beginning (in the introductory section, as suggested by the reviewer) and in the analysis of the data.

On their second point, after much consideration, I have kept the analysis of the terms and analytical tools of the Chronotopes and Mudes separated - as the concepts are not equivalent and not all the extract examples illustrate both processes (e.g. the last extract is clearly an example of Muda, but not all the others). I think I now have clarified the different aspects of both concepts and it is clearer that they are complementary rather than the same (i.e. the Chronotope referring mainly to the advancement of the biographical plot in time and space, whereas the notion of 'Muda' refers to the sociality in which the 'moment of recognition' that one has entered a new linguistic/cultural sphere happens.

I have now followed the referees' advice and have relativized some of the claims in my data to reflect a new way of looking at languagers' biographical data. I have relativized such claims appropriately throughout the article.

With regard to the comment on the extraction of the stories from the larger biographical narratives and to pinpoint exactly how these events mark a critical turning point in the languagers' views of their new spaces, I have tried to give a bit more context to the fuller stories of the language learners/languagers. I have added this both in the conclusion and in the methodology section. I hope this has partly addressed the comment about including too many abstract statements about the unhomely rather than a more grounded analysis of how this idea plays out in the narratives themselves.

Similarly, to address the referees comments on 'grandiloquent claims which are not adequately grounded in the analysis (...) I think these need to be expanded on at this point and picked up on more successfully in the analysis' I have made more connections between the theory and the extracts in order to make a more grounded analysis of the theory discussed, and in particular how the 'the world-in-the home' and 'the home-in-the world' theory is indexed in the extracts. 


\section{I have also addressed the minor points below:}

- I believe that there are no repetitive quotes by Bakhtin quotes pp. 8 and 9 any longer.

The typo in previous p.10 dis-intification = dis-identification has now been amended .

The name in previous p.12 Blommaert has now been corrected.

The phrase in previous p.25 'Is the dialogue really an intricate choreography?' has now been deleted/re-phrased.

- Referee: 2

1) I have expanded Bhabha's framework connected to the unhomely, so that the article's argument is more clearly connected with Bhabha's wider argument about the ways in which some contemporary forms of expression and engagement with the world - e.g. how day to day activities in language learning and the agency derived from it open up new possibilities for social engagement. I have done this throughout the analysis and then I have picked up on it in my final comment in the conclusion.

a) The comment by the referee 'Bhabha is thinking primarily about the experiences of the colonized and the minorities, the process of appropriating new languages requires, even at the heart of metropolitan Europe, engaging with an uncharted "beyond" that takes the subject away from the security of received positionalities' has been taken up and the idea has been incorporated in the argument in the introduction to the article.

b) As suggested, I have highlighted the connection between thresholds and third spaces, 'like the moments of liminality in which established boundaries, often invisible and unspoken, become visible and hence vulnerable, the spaces from which new agencies may start to be built that are able to construct new pasts, presents and futures (beyonds)'. I have also linked this to the current context in Europe where languagers may be able escape from the ideological positions in which they are set to grow, even if it is not as minorities.

c) The point about the connection between the "moment of crisis" and the "cracks on the walls that protected inherited categories' has also been developed to further connect Bhabha's general third space framework and my analysis through chronotopes and mudes.

d) The possibility/impossibility of accommodation within new spaces is also highlighted with reference to the extracts and examples (in particular the Serbian example where the languager feels out of control and is unable to rebuild and accommodate a new situation. e) Connections to Bhabha's concept of "beyond" have been introduced.

f) Braidotti's quotation now is now embedded in the argument that these new forms of expression that the third space affords. 
2) As requested by the second reviewer, I have also conducted a revision of the argumentative threads with the idea of making the language easier to follow to conventional sociolinguists.

Finally, I have also revised the manuscript thoroughly to address any typos pointed out by the reviewers and others that I may have missed. 